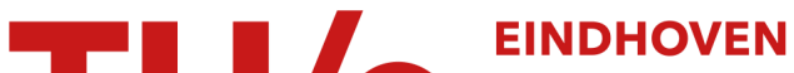 \\ UNIVERSITY OF \\ TECHNOLOGY
}

\section{The scheduler's balancing act of sensing and reacting}

\section{Citation for published version (APA):}

Larco Martinelli, J. A., Fransoo, J., Gharehgozli, A., \& Wiers, V. (2020). The scheduler's balancing act of sensing and reacting: a behavioral perspective on scheduling. International Journal of Production Research, 58(13), 3944-3955. https://doi.org/10.1080/00207543.2019.1636326

DOI:

10.1080/00207543.2019.1636326

Document status and date:

Published: 01/07/2020

\section{Document Version:}

Accepted manuscript including changes made at the peer-review stage

\section{Please check the document version of this publication:}

- A submitted manuscript is the version of the article upon submission and before peer-review. There can be important differences between the submitted version and the official published version of record. People interested in the research are advised to contact the author for the final version of the publication, or visit the $\mathrm{DOI}$ to the publisher's website.

- The final author version and the galley proof are versions of the publication after peer review.

- The final published version features the final layout of the paper including the volume, issue and page numbers.

Link to publication

\section{General rights}

Copyright and moral rights for the publications made accessible in the public portal are retained by the authors and/or other copyright owners and it is a condition of accessing publications that users recognise and abide by the legal requirements associated with these rights.

- Users may download and print one copy of any publication from the public portal for the purpose of private study or research.

- You may not further distribute the material or use it for any profit-making activity or commercial gain

- You may freely distribute the URL identifying the publication in the public portal.

If the publication is distributed under the terms of Article 25fa of the Dutch Copyright Act, indicated by the "Taverne" license above, please follow below link for the End User Agreement:

www.tue.nl/taverne

Take down policy

If you believe that this document breaches copyright please contact us at:

openaccess@tue.nl

providing details and we will investigate your claim. 


\title{
The Scheduler's Balancing Act of Sensing and Reacting: A Behavioral Perspective on Scheduling
}

\author{
José Antonio Larco Martinelli ${ }^{1 *}$, Jan Fransoo ${ }^{2}$, Amir Gharehgozli ${ }^{3}$, Vincent Wiers ${ }^{4}$ \\ ${ }^{1}$ Department of Industrial Engineering, Universidad de Ingenieria y Tecnologia - UTEC, Lima, Peru \\ ${ }^{2}$ Department of Logistics, Kuehne Logistics University, Hamburg, Germany \\ ${ }^{3}$ College of Business and Economics, California State University, Northridge, the USA \\ ${ }^{4}$ School of Industrial Engineering, Eindhoven University of Technology, Eindhoven, the Netherlands \\ jlarco@utec.edu.pe, Jan.Fransoo@the-klu.org, amir.gharehgozli@csun.edu, v.wiers@tue.nl
}




\begin{abstract}
The scheduler has been extensively studied from the point of view of their schedules, using operations research. However, the scheduler not only fulfils a decision-maker role but also an informational role, responding to requests and disruptions, both from the supply and the demand side. Responding in a timely manner to such requests and disruptions is paramount for the scheduling job. Using a field study with job shadowing of schedulers in a Fortune 500 chemical company, we characterize the scheduler's workflow in a simulation model; this allows us to discriminate between contextual factors of the scheduler's job and behavioral factors inherent to them. Furthermore, it explicitly assesses the effect of increasing the frequency sensing of the outer world on responsiveness. Our findings show that the studied schedulers prioritize sensing activities related to checking emails rather than monitoring for disruptions in a decision support system. Thus, we find a higher potential for relative improvement in terms of responding to possible disruptions shown in decision support systems rather than responding to email requests. Moreover, we show that by adjusting email frequency checking and preemption behaviors, it is possible to revert an out of control situation to finite response times.
\end{abstract}

Keywords: Scheduler; preemption; sensing and reacting; behavioral operations management 


\section{Introduction}

Schedulers exert considerable influence in production and commercial actions (Berglund et al., 2010). The literature on the scheduling problem as a classic operations research problem either dismisses some roles the schedulers fulfil or focuses on specific scheduling problems from a normative perspective (Pinedo, 1995). However, decision-makers (i.e., schedulers) can create added value to state-of-the-art operations research models, especially if long-term performance is taken into consideration (Van Donselaar, 2010). In practice, a scheduler is not only expected to allocate resources in time, but also to deal with exceptions, to identify and anticipate problems as well as to serve as an information hub for the firm's operations (McKay \& Wiers, 2003; Jackson et al, 2004).

One of the key desirable attributes of supply chains is agility, that is, the ability to respond to sudden changes in demand (Lee, 2004). Scheduling is key to support supply chain agility. Schedulers need to fulfill different roles in a timely manner. Therefore, measuring the performance of a scheduler should involve criteria related to the process of releasing a schedule as well as the product itself. Consider, for example, the case of a customer sales representative that needs an urgent response from a scheduler so that she can decide whether to accept a customer order or not. A delayed response from the scheduler to this request can have the serious implication of losing sales and this may be worse than accepting the customer order, but sub-utilizing the available resources. Indeed, in contexts where uncertainty was judged as high, Snoo et al. (2011) reported that $55 \%$ of schedulers considered being responsive more important than optimizing schedules.

In the scheduling context, responsiveness implies fulfilling the different roles of the scheduler within a reasonably expected period of time. For the decisional role of the scheduler (as described in Pinedo, 2005), responsiveness means being able to react quickly or, if possible, to even anticipate potential disruptions that arise from the current valid schedules (McKay \& Wiers, 2003) as well as to react quickly to requests from external parties to reschedule current valid schedules. For the informational role of the scheduler, responsiveness can mean being able to inform promptly a customer sales representative about the status of a customer order. Given the different meanings of responsiveness, we can then refer to responsiveness as a multidimensional concept contingent on the different roles fulfilled by the scheduler. 
To be able to achieve satisfactory levels of responsiveness, schedulers need to be able to sense any new relevant information about the state of the "world" they are responsible for. Conceptually, the world of a scheduler can stand for any resources, products, orders, materials, information flows, and requests from stakeholders for which the scheduler is directly or indirectly responsible. As the "state" of the world is in constant change (e.g., new orders, disruptions and new requests), it is necessary to find ways to sense such a world. Sensing the world implies a variety of monitoring activities that consume time whether the scheduler is checking incoming emails for new requests or reviewing stocks for detecting disruptions. All these monitoring activities take time that could otherwise be spent in other tasks to actually react to changing circumstances in the sensed world. Most studies have not focused on how schedulers balance the need for sensing and the need for reacting at their job to attain responsiveness (Sanderson, 1991; Wiers and van der Schaaf, 1997; Crawford et al., 1999). In this article, we contribute to the field of scheduling by building a theory on how schedulers trade-off different sensing and reacting actions with different responsiveness dimensions.

Based on actual observation data from multiple case studies, we reconstruct the main characteristics of the scheduler's timeline by proposing a simulation-based workflow model that includes different balancing of sensing and reacting behaviors. Moreover, the model allows to isolate the effect of the scheduler's inherent behavioral factors (e.g., the probability that a scheduler checks its emails after finishing a task) from the effect of contextual factors to which the scheduler is subject to (e.g., the rate at which incoming email requests occur). While the discretion to spend more time on a task has been modeled (Hopp et al., 2009; Batt \& Terwish, 2012; Tan \& Netessine, 2014), our contribution focuses on the control of task sequences.

Even if the exact trade-offs of sensing behavior to achieve different dimensions of responsiveness may be non-generalizable and context-dependent, the paper does allow for identifying emergent patterns and propositions to be tested in larger contexts. Moreover, the workflow model structure based on in-depth multiple case studies may be used to make staffing decisions and evaluate the division of labor in scheduling departments. More so, in the context of multinational firms such as Dow Chemical, AB-InBev centralizing their scheduling functions in one location (Kok, 2015). This paper is organized as follows. Section 2 reviews the current understanding of scheduling. Section 3 describes the research methodology where we use multiple cases to derive a detailed 
workflow simulation model. Our findings from the case study and simulation model are reported in Section 4. Implications of the findings are given on Section 5.

\section{Literature review}

Most initial efforts to characterize the workflow of the scheduler assumed a linear sequence of tasks, distinguishing repetitive tasks from exceptional tasks (McKay and Wiers, 2003). Similarly, case studies by Jackson et al (2004) and Webster and Azizoglu (2001) highlight the need for monitoring, capturing and communicating information. This last attribute is important as for anticipating problems, the act of sensing is required. Decision Support Systems, such as Advanced Planning Scheduling systems (APS) (Wiers and Kok, 2017) are often used as a prime source of information to sense and monitor the situation of production orders, customer orders and inventory. A workflow model of the scheduler should then explicitly include the action of sensing in decision support systems.

The linearity of the flows implicitly proposed by these descriptive models can be a natural consequence of not considering time explicitly. However, the act of monitoring means that the task is non-linear. Indeed, Romero Silva et al. (2015) proposed to view the actual scheduling job as a feedback control system that includes a sensor of the actual manufacturing environment and the scheduler, resulting in a non-linear sequence of steps with a sensing and reacting loop. In fact, Gralla et al., (2016) showed that the scheduler's perception evolves while scheduling and as a result, sensing evolves. At the same time, Gasser et al. (2010) identified that decisions, disruptions and clarifications all trigger information exchange between the scheduler and other stakeholders, generating an update of the general state of knowledge to the scheduler and the stakeholders involved.

One of the main dynamic aspects of scheduling, is the need for re-scheduling, namely due to unforeseen events (Subramanian et al., 2005). Reformulating re-scheduling problems is non-trivial and thus may need human intervention to describe the new situation. It is key to identify the origin of disruptions to be able to model their impact on responsiveness. In a study by Berglund et al. (2010), they describe the interactions of the scheduler with demand and supply sides can result in understanding the root of disruptions. Thus, a workflow model of the scheduler needs to consider both sides explicitly as the scheduler job acts as a hinge between supply and demand within the firm.

*Corresponding author: jlarco@utec.edu.pe, T: (511) 2305000 Ext. 4272, Jr. Medrano Silva 165, Barranco, Lima, Peru. 
Re-scheduling actions imply the need of communication with the relevant departments for the new schedule to be implemented (MacCarthy \& Wilson, 2004). Production managers need to be informed as to the new schedules to be executed and sales representatives need to know changes in delivery times to inform their customers. At the same time, communication is also needed to be able to solve task interdependencies between different schedules (De Snoo \& Wezel, 2011). Besides re-scheduling, changes in requirements for raw materials, production, and the need for communication also arises from the fact that schedulers often function as information hubs as shown by the field studies of Jacskon et al. (2004) and Larco et al. (2018).

Furthermore, the communication medium has important implications for the workflow. Emailing is ubiquitous to the modern white-collar workplace of which the schedulers take part. The main characteristic of the email medium is that it enables asynchronous communication.

Asynchronous communication has the benefit that the person does not need to be preempted while the other sends the email and this is reflected on Renaud et al.'s (2006) finding that the perceived disruption of emails is significantly lower than that of synchronous face-to-face and telephone communication.

Although the scheduler's expectation of replying to face-to-face communication can be measured in the order of seconds, with email, such expectation can be measured in the order of minutes (Jackson et al., 2001). A related result by Reanud et al. (2006) explains that although the time used for sending email is of a relatively negligible magnitude, the time spent for monitoring continuously incoming emails is significant.

Monitoring email requires an explicit effort to actually check email, and implies decision latitude of self-initiated tasks (Czerwinski et al., 2004). This activity will in effect amount to sensing. It is via email that schedulers can become aware of informational or action requests of their other stakeholders, both, from the supply and demand side. Engaging in monitoring email too often can make work more fragmented, postponing actual responding activities, and a workflow simulation ought to capture such trade-off.

Another way by which scheduler exert discretion is that of preempting the performing of one task to perform another one. Preemption has been reported to be a pervasive phenomenon in whitecollar work (Jett \& George, 2003). Besides its pervasiveness (see Gonzales et al. (2004) and Mark et al. (2005)), the fact that preemption violates Shortest Processing Time rule for minimizing 
completion times (Pinedo, 2005) and is associated to cognitive switching costs (including loss of accuracy and additional switching time) (Monsell, 2003), can affect responsiveness.

\section{Methodology}

The scheduling tasks have been described as a combination of dealing with both routine and exceptional situations that require problem solving (Sanderson, 1991; Wiers \& Van Der Schaaf, 1997). It is precisely the requirement to deal with "exceptions" that have made difficult both in practice and in scientific work to characterize systematically the working day of a scheduler. To obtain empirical evidence of these complex sensing behaviors, laboratory experiments remain too limited in scope and rich field data becomes necessary. This implies that compared to other case studies in scheduling, we did not observe the tasks of a scheduler in isolation but rather map their interdependencies in terms of workflow, specifying how each task was triggered, and checking whether a task was effectively completed right from the start or resumed later.

To study how sensing occurs in scheduling, we conducted multiple case studies within the scheduling department of a large Fortune 500 chemical company where all the European operations where controlled and scheduled. Multiple case studies allowed for an in-depth analysis of a complex operational phenomenon, that of workflows of a scheduler in its natural setting for theory building (Voss et al., 2002; Eisenhardt and Graebner, 2007), allowing for operationalizations of key variables relating to contextual and behavioral factors that relate to responsiveness. The workflow model provided the logic to evaluate a relationship between the contextual and behavioral factors with responsiveness.

The in-depth study involved two main stages: the data collection and the simulation study with data processing. The data collection was used to identify relevant contextual and behavioral variables (see Section 3.1) and estimating their value. The discrete event simulation study allowed for assessing the situation as-is and evaluating the effects of sensing behaviors on responsiveness (see Section 3.2). As on our study the scheduler served the role of focal point, and incoming requests where considered exogenous, thus, other actors where not explicitly modelled and a distributed agent simulation was not used. 


\subsection{Data collection}

Seven schedulers were selected out of a total of 12 that were co-located in a single facility. While selecting the schedulers from the same firm allowed for common company policies that enable easier comparison of flows, the schedules were selected to ensure sample diversity in terms of number of Stock Keeping Units and plants controlled. All of the schedulers had at least three months of experience at the job. The events in the work of a scheduler where observed for a total of 19 entire scheduler-days, each day consisting of an 8-hour shift. At a minimum, each scheduler was observed using a shadowing procedure for two days (Czarniawska-Joerges, 2007).

The schedulers studied controlled production batches and customer deliveries and were expected to produce high quality schedules that met company profitability business rules as well as customer commitments. Moreover, they were expected to be able to respond quickly to customer sales representatives, plant managers, supply chain planners and logistics planners. Apart from a weekly planning meeting with supply chain planners, the schedulers had almost total discretion as to which tasks to perform and when. For making their scheduling decisions, schedulers had offline Ganttlike tools and techniques (for example, see section 3.2). However, no actual formal optimization techniques where used.

The schedulers were observed by a team of four researchers and took a day to familiarize with the scheduling work of each scheduler, including the scope of their tasks, the major decision support systems used for decision making and monitoring activities as well as their main stakeholders. The main aim of this familiarization day was to be able to quickly identify the type of task accomplished without needing to ask questions once the actual observation of the study starts making the observations of the scheduler more grounded (Suddaby, 2006). To reduce any impact in the behavior shown by schedulers, the schedulers where assured confidentiality and told to engage in their work as they normally do. The schedulers were informed that the purpose of the study was to be able to identify the main tasks at which schedulers often engage.

The researcher, assigned to a scheduler, noted the starting and finishing time of each task and noticed if the task was finished, or preempted. The granularity of the task was defined such that each task had to have a deliverable for an external or internal party. A deliverable in the observed context included a piece of information, a schedule, a modified schedule release, or a complete monitoring activity of production. Each task may require multiple sub-tasks like analyzing stock 
movements, verifying production capacity and responding to customer representatives to see if an additional customer order can be accepted.

Brief descriptions of the purpose of the task were given. The tasks were also categorized in different types. For the purposes of our analysis and based on our discussions in Section 2, four categories became relevant: 1) email checking tasks, 2) monitoring stocks and production orders tasks, 3) addressing requests from external parties (including, re-scheduling, requests for information) and 4) re-scheduling activities triggered by monitoring stocks and production orders activities. To assure that the same task that is preempted is not counted as a new task, unique identifiers were used. In addition, each time emails were checked, the number of emails that the scheduler had to pay attention to was recorded. Finally, information about the workflow was provided distinguishing the following categories: 1) Task is finished, 2) Task is preempted to check email, 3) Task is preempted to start monitoring activity and 4) Task is preempted to switch to another preempted task.

\subsection{Data processing and simulation study}

To reconstruct the timeline of the tasks performed, some post-processing of the data was required. The researchers reviewed each other's data set collected to assure uniformity in the classification and level of granularity of tasks. In $5 \%$ of the cases, certain tasks were merged into one, following the guidelines of one deliverable. At the same time, only in $2 \%$ of the cases, assigned task types were changed for others ones, when reviewed by a different researcher.

The timelines observed were fragmented and disorganized as shown in an excerpt of a typical timeline in Table 1. To organize the data, we used Hopp et al.'s (2009) proposed framework for modelling white-collar work and modified it according to our observations. In this way, tasks where classified as been triggered endogenously by the scheduler himself, or exogenously by external requests. Furthermore, sensing activities were considered as endogenous, and reacting to requests or disruptions were considered as exogenous. 
Table 1: An excerpt of a typical timeline of a scheduler

\begin{tabular}{|c|c|c|c|c|c|c|c|}
\hline Task description & Flow & Task ID & 9:45 & $10: 00$ & 10:15 & $10: 30$ & Workflow \\
\hline Issuing production orders sequences & Responding & Scheduling 1 & & & & & Preemption \\
\hline Checking capacity and stocks & Sensing Decision Support & & & & & & Finished \\
\hline Asks CSR to delay orders to free capacity at the Bulk plant & Responding & Scheduling 1 & & & & & Preemption \\
\hline Issue with deliv ery note: customer requires material later & Responding & & & & & & Finished \\
\hline CSR asks: Checking if out of stock is solved & Responding Email Request & & & & & & Finished \\
\hline Checks mail, FYI, sales issue & Sensing Email Requests & & & & & & Finished \\
\hline Updating drum filling execution plan & Responding & Code002DR & & & & & Preemption \\
\hline Break/idle & Break & & & & & & Finished \\
\hline Updating drum filling execution plan -asking CSR to make order change & Responding & Code002DR & & & & & Finished \\
\hline Checking e-mails & Sensing Email Requests & & & & & & Finished \\
\hline
\end{tabular}

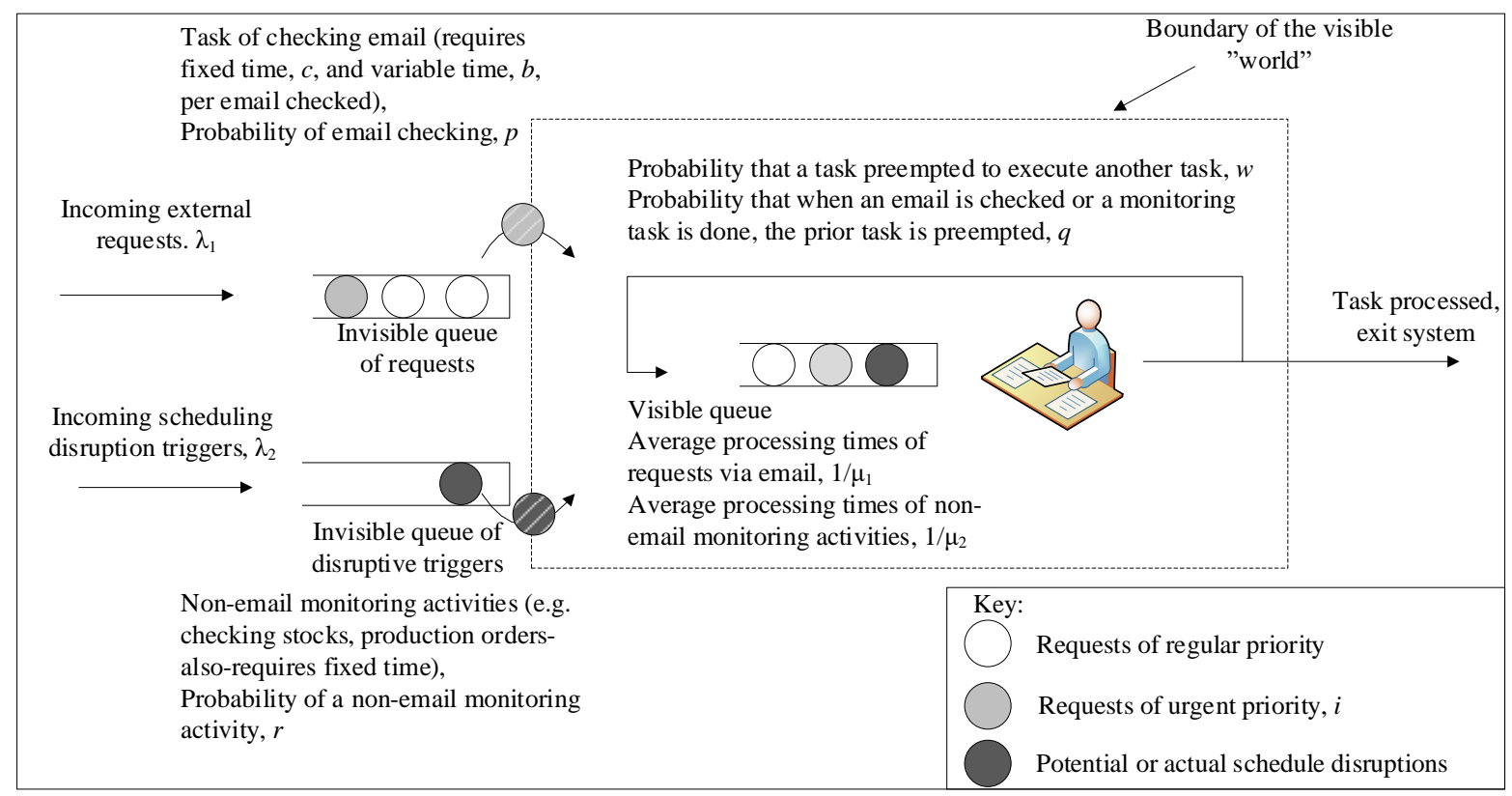

Figure 1: Workflow description with the scheduler as a focal point

Given the scheduler as the focal point of a workflow model, the first obvious pattern that emerged from the data collection, is that the scheduler has limited knowledge of the world that needs to be controlled. This is consistent with two schedulers thinking aloud: "I need to check whether my production orders have been executed or not" and "let me check my email and see if there are any exceptional incoming client requests from the Customer Sales Representatives."

The scheduler can only execute tasks that are in her visible queue. However, the only way the visible queue can become filled is by engaging in monitoring activities where the scheduler senses the outer world. The visible queue would then be filled with responding tasks, either responding to email requests or addressing disruptions sensed at the decision support system. From the data collected, agreed with it was possible to distinguish between two main types of monitoring activities. The first type of monitoring activities involved that of checking requests accumulated 
in an email inbox allowing for asynchronous communication (i.e. the scheduler could decide when to react to such e-mail). The second type of monitoring activities consisted of checking production orders, stocks and demand fluctuation in decision support systems. At the same time, in the cases identified, there was seldom relevant synchronous communication that required response from the scheduler. This can be explained with the fact that the operations scheduled were outside the control towers and therefore the main sensing sources were either email or the decision support system.

In both cases, the act of monitoring, implied verifying if further tasks were needed to be executed. Each time the scheduler engaged in email checking, an undetermined number of requests from the scheduler's stakeholders was waiting for the scheduler's reactions. The cases studied also made it evident from the perception of the schedulers that not all incoming requests were urgent. For example, a request of urgent nature was to reply to a Customer Sales Representative whether a given customer order would be delivered late to a customer whereas a request that is important, but non-urgent, was a request to the schedule to inform about candidate dates for scheduling a maintenance period.

In the case of monitoring production orders and stocks, a number of re-scheduling triggers were in the queue. Re-scheduling triggers mostly included potential or real disruptions from supply origin (e.g. out-of-stocks in raw materials, production orders not met) or demand origin (e.g. unexpected incoming orders, canceled orders) as well as unexpected opportunities for improving a schedule such as a production resource that becomes idle earlier than expected (this happened in only $10 \%$ of cases observed).

In both types of monitoring or sensing activities, the mere act of performing them involved a processing time. For the case of email checking, it involved a fixed time that is independent of how many requests existed in the queue. For simplicity purposes, it was assumed that due to the short duration and variation, the time required for checking email was deterministic. At the same time, email checking involved a random processing time directly proportional to the number of requests in an email inbox that required attention, excluding spam emails. For the case of checking production orders, stocks and demand fluctuations, a similar simplified fixed assigned time was assumed for the workflow model. 
For an adequate representation of the scheduler's job it was also necessary to describe the behavior of schedulers in terms of controlling what task to perform next. First, we needed to distinguish between two cases, whenever the queue of visible tasks to the scheduler is empty (i.e., Work in Progress $($ WIP) $=0$ ) and whenever it was not (i.e., WIP >0). We only identified on average $5 \%$ of cases where the visible queue was empty. In these cases, schedulers engaged in monitoring tasks to avoid idle time.

When the visible queue was non-empty, describing the control policies used by the schedulers was more complex. Our first observation from the cases studied is that despite the fact that preemptions were important, on average $25 \%$ of tasks were preempted, with a maximum of $31 \%$ in the case of one scheduler, implying that monitoring tasks where mostly triggered after a task was finished, not preempted. This has important implications for modeling the workflow, as it means that it is a better approximation to model the start of monitoring (sensing) activities conditional on a task being finished or not, instead of a time-based stochastic process. Thus, in our simulation, we modelled the start of monitoring (sensing) activities conditional on whether a non-sensing task was preempted or not. For simplicity, and because it is difficult to verify whether a sensing task is brought to completion, we assume that the sensing tasks are not preempted. In this way, we built a probability tree as described in Figure 2.

The schedulers also reported that whenever urgent requests via email and addressing (potential) disruptions in the schedule were signaled in the decision support system, these were urgent and put in front of the queue. Next, we observed that when the visible queue of tasks was empty, the schedulers engaged in either type of monitoring activities to avoid idleness. By analyzing cases where the visible queue was empty, we found that schedulers involved in email checking versus other monitoring activities roughly at a ratio of 3 to 1 . 


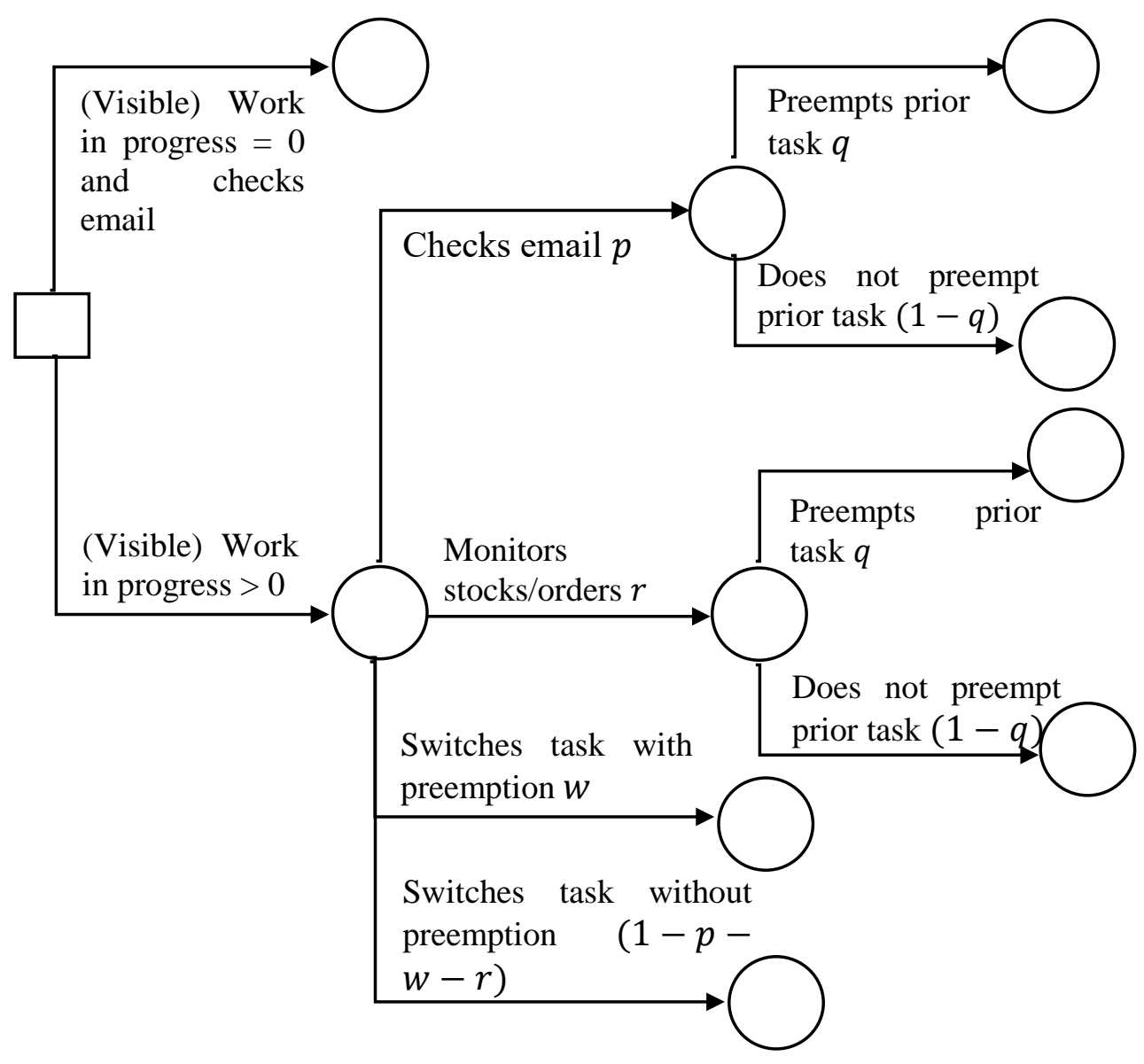

Figure 2: Probability tree conditioning on when a task is started

The study observed 1595 cases (completed and incomplete tasks) distributed among 7 schedulers. Although our focus of the case studies was to obtain the workflow structure, the data collected allowed for estimation of the probability density distribution parameters of task triggers arrival processes, task duration distribution processes, and conditional probabilities. To simplify and standardize the comparative analysis across schedulers we modelled both arrival and task duration processes as exponential distributions that require only one parameter (i.e. the first moment). This modelling assumption can also be justified on theoretical grounds (Law, 2015), considering that while the arrival processes can be seen as Poisson processes, the duration processes consist of tasks where most have minimal duration and a few have longer ones. Table 2 provides an overview on the different methods used for estimating the parameters used as input in our simulation model. 
Regarding the simulation output variables, we distinguish across three main raw responsiveness dimensions: 1) responsiveness to regular requests, 2) responsiveness to urgent requests and 3) responsiveness to (potential) disruptions to current valid schedules. We define raw-responsiveness as the time taken for a request or a potential scheduling disruption to be completely addressed by the scheduler.

Table 2: Procedures for estimating parameters

\begin{tabular}{|c|c|}
\hline Parameter & Estimation procedure \\
\hline \multirow{2}{*}{$\begin{array}{l}\text { Average arrival rate of } \\
\text { requests by email, } \lambda_{1}\end{array}$} & \multirow{4}{*}{$=\frac{\lambda_{2}}{\text { Total Number of request in all non }- \text { email monitoring episodes }}$} \\
\hline & \\
\hline \multirow{2}{*}{$\begin{array}{l}\text { Average arrival rate of } \\
\text { requests by non-email } \\
\text { monitoring activities, } \lambda_{2}\end{array}$} & \\
\hline & \\
\hline \multirow{2}{*}{$\begin{array}{l}\text { Average processing times of } \\
\text { requests via email, } 1 / \mu_{1}\end{array}$} & \multirow{2}{*}{$1 / \mu_{1}=\frac{\text { Total time spent in processing email requests }}{\text { Number of email requests processed }}$} \\
\hline & \\
\hline \multirow{2}{*}{$\begin{array}{l}\text { Average processing times of } \\
\text { non-email monitoring } \\
\text { activities, } 1 / \mu_{2}\end{array}$} & $\mu_{1}=\frac{\text { Total time spent in processing non }- \text { email requests }}{}$ \\
\hline & $1 / \mu_{2}=\frac{\text { Number of non - email requests processed }}{\text { number }}$ \\
\hline \multirow{2}{*}{$\begin{array}{l}\text { Probability of email checking, } \\
p\end{array}$} & $n=$ Total number of email checking episodes \\
\hline & $p=\overline{\text { Total number of episodes when WIP }>0}$ \\
\hline \multirow{2}{*}{$\begin{array}{l}\text { Probability of a non-email } \\
\text { monitoring activity, } r\end{array}$} & Total number of non - email monitoring episodes \\
\hline & Total number of episodes when WIP >0 \\
\hline \multirow{2}{*}{$\begin{array}{l}\text { Conditional probability that } \\
\text { given a sensing activity is } \\
\text { done, the prior task is } \\
\text { preempted, } q^{[1]}\end{array}$} & $=$ Total number of prior episodes that are preempted \\
\hline & Total number of sensing episodes \\
\hline \multirow{2}{*}{$\begin{array}{l}\text { Probability that a task is } \\
\text { preempted to execute another } \\
\text { task in the queue, } w\end{array}$} & $w=$ Total number of episodes preempted to perform another task in queue \\
\hline & $W=\frac{\text { Total number of episodes when } W I P>0}{}$ \\
\hline $\begin{array}{l}\text { Probability that a request is of } \\
\text { an urgent type, } i\end{array}$ & $i=$ Self-reported, expert knowledge opinion \\
\hline Fixed email checking time, $c$ & $\begin{array}{r}c=\text { Intercept in linear regression estimate of time spent to process requests } \\
\text { via email }\end{array}$ \\
\hline $\begin{array}{l}\text { Variable email checking time, } \\
b\end{array}$ & $\begin{array}{r}b=\text { Slope in linear regression estimate of time spent to process requests via } \\
\text { email (using all data) }\end{array}$ \\
\hline
\end{tabular}

${ }^{[1]}$ Here we make no distinction between preempting for checking email or disruptions in the decision support system. We pool the data to obtain more accurate estimates.

\section{Simulation study results}

We used Arena TM version 15, as a reliable and well-known discrete event simulation software to implement the simulation model as described in Section 3. We simulated 30 runs of 240,000 minutes, plus 60,000 warm-up minutes each, as we were interested in the analysis of steady-state behavior (Rossetti, 2015). We calibrated the replication lengths such that we obtained errors in the 
responsiveness variable that were bounded to less than 0.01 minutes for a 0.95 confidence interval (Law, 2015).

Table 3 shows the environmental parameters and behavioral parameters collected in each case study using the procedure detailed in Table 2 to serve as input for the simulation. Already from Table 3, it becomes apparent that there is considerable variability in terms of the arrival rate of requests via email and the arrival rates of disruptions; in fact, the ratio of the maximum to the minimum result is a factor of 4.1 and 3.9 respectively. The correlation, between both arrival rates, though positive, is weak $(\rho=0.11)$, indicating heterogeneity in the work-context. Similarly, the mean duration of processing email requests and disruptions found in the decision support system show high variability. Thus, the policies to obtain minimum responsive times would likely vary across schedulers.

However, what is noteworthy is that there is a high correlation $(\rho=0.86)$ between the email arrival rate and the mean email processing time, suggesting that there is adaptation of the working speed to match that of the workload. This result is consistent with Hopp et al. (2009) who finds out that judgment is frequently required to determine how much time to allocate to a task. In practice, taking together the high variability of arrival rates and processing times implies that it is difficult for a manager to quantify the workload of schedulers a-priori.

In terms of the scheduler workflow behavior, Table 3, shows a consistent result across all schedulers: the frequency of checking email requests is higher than that of checking real and potential disruption in the decision support system, i.e. $p>r$. However, the probability of preemptions does vary widely across schedulers, implying important individual differences. 
Table 3: Data collected in the case study

\begin{tabular}{|c|c|c|c|c|c|c|c|}
\hline \multirow{2}{*}{$\begin{array}{l}\text { Parameters } \\
\text { Scheduling environmental parameters }\end{array}$} & \multicolumn{7}{|c|}{ Scheduler } \\
\hline & 1 & 2 & 3 & 4 & 5 & 6 & 7 \\
\hline $\begin{array}{l}\text { Mean time between arrivals of requests via e- } \\
\text { mail, } 1 / \lambda_{1}\end{array}$ & 5.86 & 14.78 & 7.58 & 12.63 & 15.55 & 22.74 & 23.96 \\
\hline $\begin{array}{l}\text { Mean time between arrivals of non-email } \\
\text { monitoring activities, } 1 / \lambda_{2}\end{array}$ & 524.00 & 480.35 & 750.00 & 192.14 & 480.36 & 510.35 & 740.00 \\
\hline $\begin{array}{l}\text { Average processing times of requests via email, } \\
1 / \mu_{1}\end{array}$ & 3.75 & 7.35 & 3.89 & 5.65 & 8.13 & 7.79 & 7.73 \\
\hline $\begin{array}{l}\text { Average processing times of non-email } \\
\text { monitoring activities, } 1 / \mu_{2}\end{array}$ & 8.41 & 16.00 & 7.96 & 15.50 & 6.60 & 6.50 & 7.88 \\
\hline Probability that a request is of an urgent type, $i$ & 0.20 & 0.10 & 0.20 & 0.20 & 0.20 & 0.10 & 0.10 \\
\hline Fixed email checking time, $c$ & 1.00 & 2.00 & 1.50 & 2.50 & 2.00 & 2.50 & 3.00 \\
\hline Variable email checking time, $b$ & 0.90 & 0.90 & 0.90 & 0.90 & 0.90 & 0.90 & 0.90 \\
\hline Behavioral parameters & 1 & 2 & 3 & 4 & 5 & 6 & 7 \\
\hline Probability of email checking, $p$ & 0.69 & 0.21 & 0.67 & 0.23 & 0.15 & 0.47 & 0.46 \\
\hline Probability of non-email monitoring activity, $r$ & 0.10 & 0.10 & 0.16 & 0.27 & 0.10 & 0.08 & 0.04 \\
\hline $\begin{array}{l}\text { Conditional probability that given that sensing } \\
\text { activity is done, the prior task is preempted, } q\end{array}$ & 0.25 & 0.26 & 0.33 & 0.21 & 0.13 & 0.03 & 0.25 \\
\hline $\begin{array}{l}\text { Probability that a task is preempted to execute } \\
\text { another task in the queue, } w\end{array}$ & 0.08 & 0.15 & 0.07 & 0.13 & 0.05 & 0.03 & 0.05 \\
\hline
\end{tabular}

The results of the actual situation are shown in Table 4, highlighting two unstable cases, Scheduler 1 and 3. Compared to the other schedulers, Schedulers 1 and 3, have relatively high $\lambda_{1} /{ }_{1}$ ratios, as well as relatively high probabilities of email checking, $p$, after a task is started whenever work in progress is positive. Remarkably, Schedulers 1 and 3, response times return back to stability if $p=q=w=0$, i.e. by eliminating preemptions and checking email only when the visible queue is empty.

*Corresponding author: jlarco@utec.edu.pe, T: (511) 2305000 Ext. 4272, Jr. Medrano Silva 165, Barranco, Lima, Peru. 
Table 4: Response times to different types of tasks by different schedulers

\begin{tabular}{lccccccc}
\hline & $\begin{array}{c}\text { Scheduler } \\
1\end{array}$ & $\begin{array}{c}\text { Scheduler } \\
2\end{array}$ & $\begin{array}{c}\text { Scheduler } \\
3\end{array}$ & $\begin{array}{c}\text { Scheduler } \\
4\end{array}$ & $\begin{array}{c}\text { Scheduler } \\
5\end{array}$ & $\begin{array}{c}\text { Scheduler } \\
6\end{array}$ & $\begin{array}{c}\text { Scheduler } \\
7\end{array}$ \\
\hline $\begin{array}{l}\text { Response time to urgent } \\
\text { requests (min) }\end{array}$ & $\infty$ & 26.40 & $\infty$ & 23.58 & 29.16 & 23.34 & 24.60 \\
$\begin{array}{l}\text { Response time to regular } \\
\text { requests (min) }\end{array}$ & $\infty$ & 37.44 & $\infty$ & 31.98 & 36.06 & 25.68 & 27.60 \\
$\begin{array}{l}\text { Response time to real } \\
\text { and potential disruptions } \\
\text { (min) }\end{array}$ & $\infty$ & 28.56 & $\infty$ & 24.72 & 38.34 & 49.50 & 56.76 \\
\hline
\end{tabular}

To further explore the reasons of such instability, additional experiments were conducted varying $p$, while making all other parameters constant and eliminating the possibility of preemptions (i.e., $r=w=0$ ). In this way, Figure 3, shows that for scheduler 7, increasing $p$ starting from 0 , increases the response time to urgent requests, until a certain limit is reached, where rapidly the system becomes unstable. For other schedulers as shown in Table 5, increasing $p$ starting from 0 , actually yields the opposite result: a decrease in response times until a certain limit is reached and the system rapidly unstable.

An intuitive explanation for this is that when utilization is relatively low, the visible queue becomes zero more often and thus, the scheduler can check email more often and given the rate of incoming urgent email checking email, there may be no need to check email more often. If, on the contrary, utilization is relatively high, and the proportion of urgent requests is limited, the visible queue is more often filled with regular requests and no urgent requests. Thus, checking email more often can yield an advantage in terms of response time. To test this, an experiment was conducted with the same Scheduler 7, without loss of generality, by doubling the email processing utilization (i.e. multiplying the mean duration of email request processing), finding that indeed a reversal of the pattern occurs as depicted by Figure 3 using a high utilization scenario.

Similarly, preemptions for email checking behave as substitute for the parameter $p$. This means that whenever the general pattern is decreasing, preemptions actually reduce response times to urgent requests, whereas if the general pattern is increasing, preemptions are detrimental to urgent requests response times. These effects are shown with arrows labeled 1 and 2, respectively in Figure 3.

*Corresponding author: jlarco@utec.edu.pe, T: (511) 2305000 Ext. 4272, Jr. Medrano Silva 165, Barranco, Lima, Peru. 
Table 5: Gaps to the efficient frontier of responsiveness from real schedulers' behavior

\begin{tabular}{|c|c|c|c|c|c|c|}
\hline & $\begin{array}{l}\text { Increasing } p \text {, email checking } \\
\text { prob. }\end{array}$ & $\begin{array}{l}\text { Best } \\
p^{*} \\
\text { value }\end{array}$ & $\begin{array}{l}\text { Actual } p \\
\text { value }\end{array}$ & $\begin{array}{l}\text { Utilization } \\
\text { ratio } \\
\left(\rho=\lambda_{1} / \mu_{1}\right)\end{array}$ & Deviation & Observation \\
\hline Scheduler 1 & Decreasing with asymptote at $\mathrm{p}^{*}$ & 0.6 & 0.7 & 0.6398 & 0.1 & Unstable \\
\hline Scheduler 2 & Increasing & 0 & 0.2 & 0.4970 & 0.2 & Stable \\
\hline Scheduler 3 & Decreasing with asymptote at $\mathrm{p}^{*}$ & 0.2 & 0.7 & 0.5136 & 0.5 & Unstable \\
\hline Scheduler 4 & Increasing & 0 & 0.2 & 0.4475 & 0.2 & Stable \\
\hline Scheduler 5 & Decreasing with asymptote at $\mathrm{p}^{*}$ & 0.7 & 0.1 & 0.5229 & -0.6 & Stable \\
\hline Scheduler 6 & Increasing & 0 & 0.5 & 0.3426 & 0.5 & Stable \\
\hline Scheduler 7 & Increasing & 0 & 0.5 & 0.3226 & 0.5 & Stable \\
\hline
\end{tabular}

*Corresponding author: jlarco@utec.edu.pe, T: (511) 2305000 Ext. 4272, Jr. Medrano Silva 165, Barranco, Lima, Peru. 


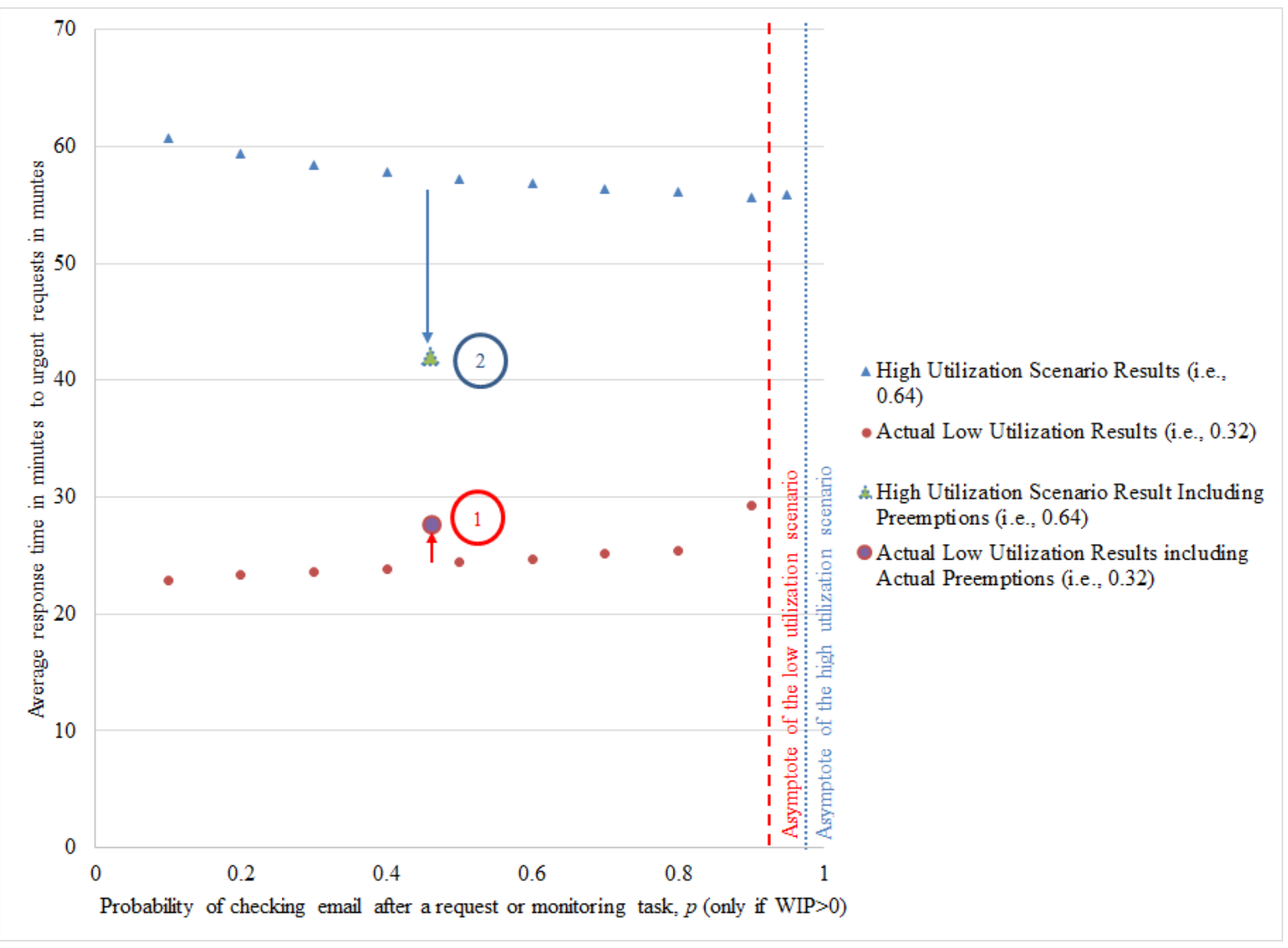

Figure 3: Effect of email checking on responsiveness for urgent email requests for Scheduler 7

However, since responsiveness is multidimensional, responding to urgent email requests is not the only objective that matters. Responding to disruptions that appear through the decision support systems can be also important. In this case, increasing $p$, yields always, independently of the workload, increased response times for real and potential disruptions that can be sensed from the decision support system as shown in Figure 4 for Scheduler 7. 


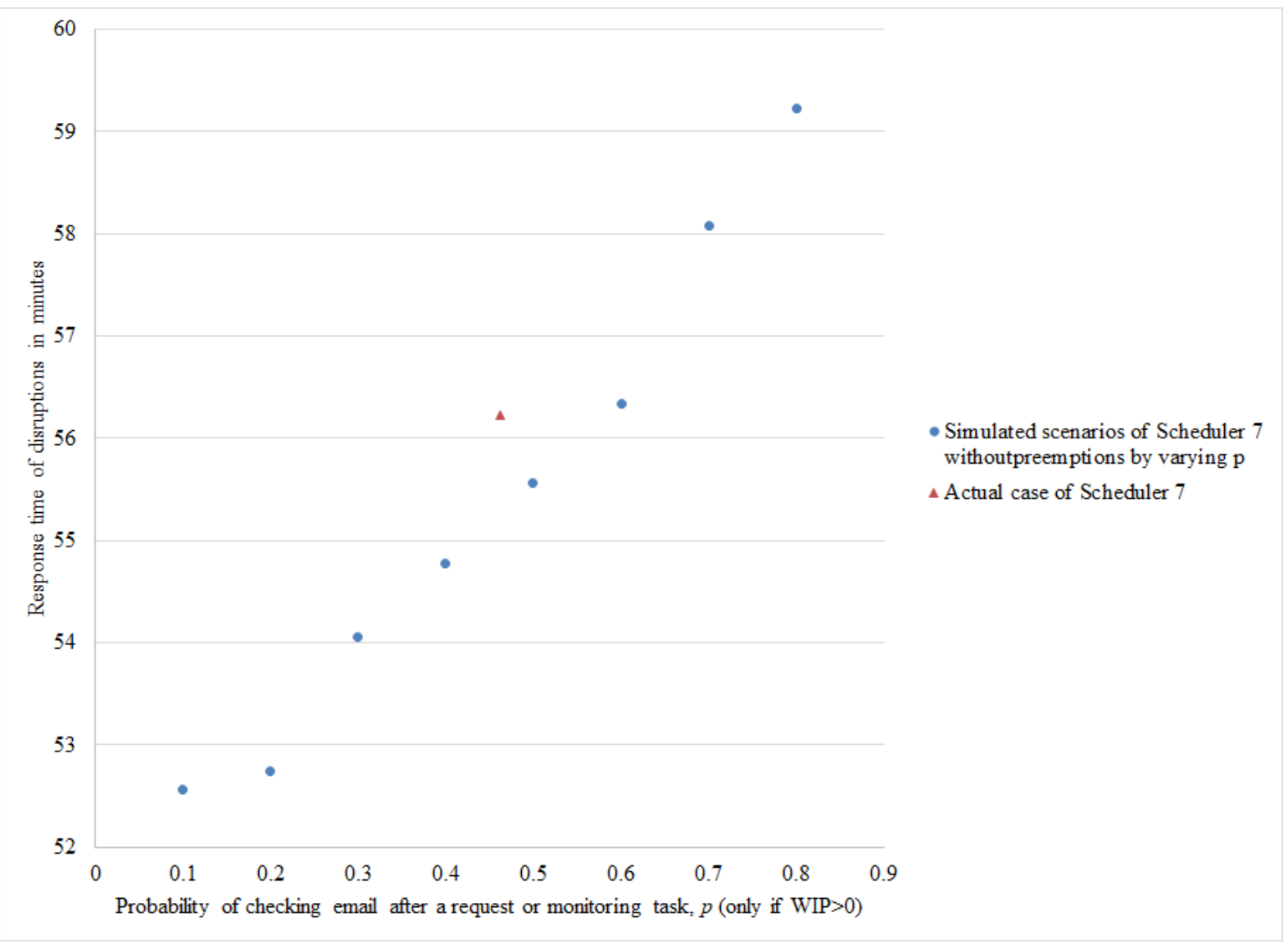

Figure 4: Effectiveness of email checking in disruption responsiveness for Scheduler 7

For this reason, we also studied the patterns of non-dominated solutions for each scheduler. To achieve this, we varied first parameter $r$ (such that $p+r<1$ ) that is, the probability that if a task is started when the visible queue is non-empty, the next task will be that of a monitoring task. Then, for any given parameter of $r$, we found the best responsiveness time for incoming email requests and also recorded the corresponding response time to disruptions that can be verified in the decision support system. In this way, a trade-off of two responsiveness dimensions was created as shown in Figure 5 for Scheduler 7.

Figure 5 shows that for Scheduler 7, the actual case is off the trade-off curve of non-dominated solutions. This means that the solutions can be improved in both objectives simultaneously. We labeled the possible improvement in responsiveness to external requests as the horizontal gap and we labeled the possible improvement in responsiveness to disruptions that can be sensed via a decision support system as the vertical gap. From Figure 5, it can be seen that the vertical gap is considerably larger than the horizontal gap and this is true for other schedulers as well as shown 
in Table 6. This means that, the current email and decision support system sensing policies have orders of magnitude more to improve in relative terms for the dimension of responsiveness to disruptions than responding to incoming urgent email. A possible explanation for this may be that given email requests are received more often and are concrete calls for action these receive disproportionately more attention than potential disruptions that occur less often and that require some cognitive processing.

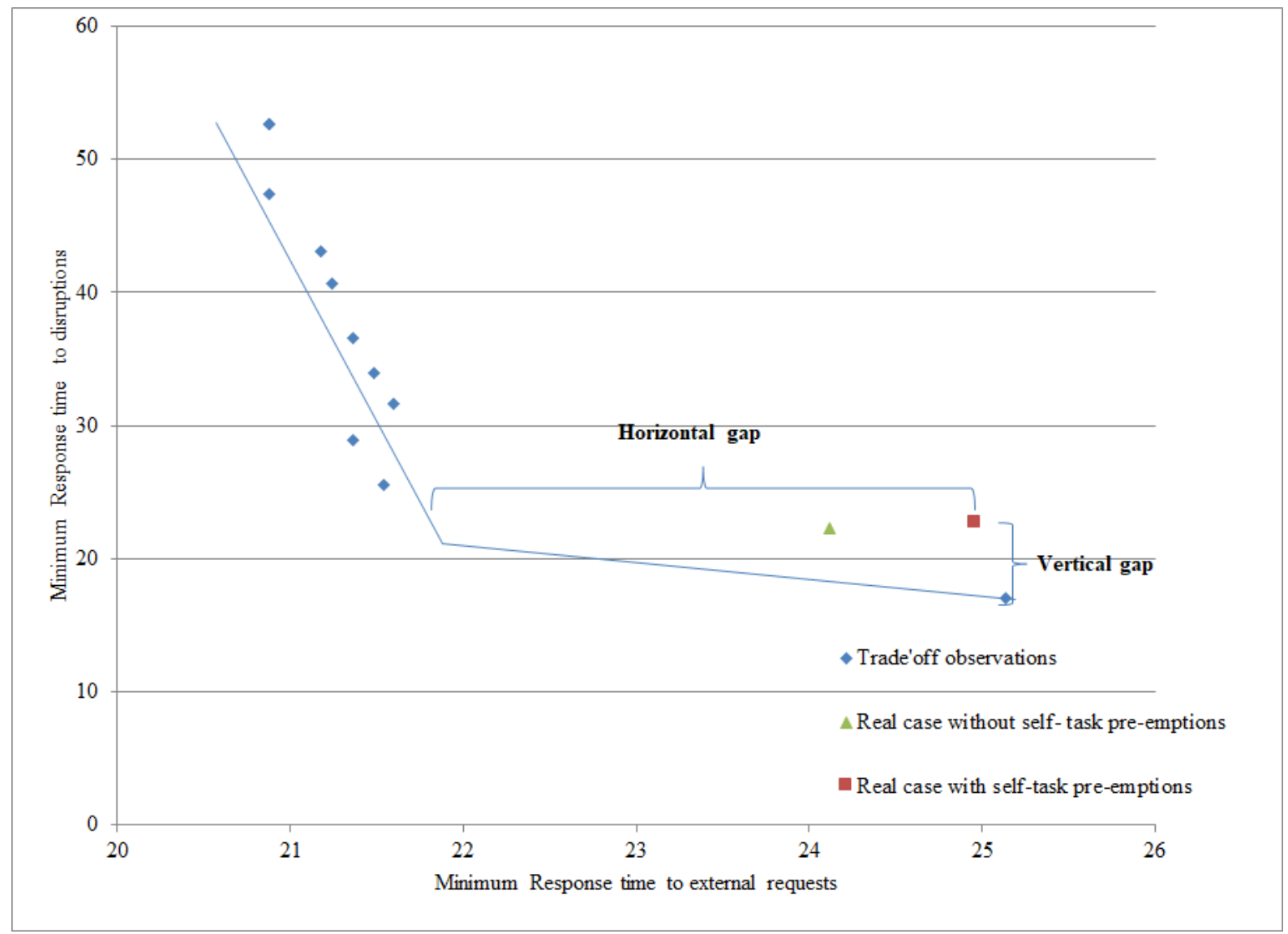

Figure 5: Responsiveness for (potential) scheduling disruptions, normative and actual policies

Adapted from Larco et al. (2015)

*Corresponding author: jlarco@utec.edu.pe, T: (511) 2305000 Ext. 4272, Jr. Medrano Silva 165, Barranco, Lima, Peru. 
Table 6: Distance to normative efficient frontier from actual situations per scheduler

\begin{tabular}{|c|c|c|c|c|}
\hline & \multicolumn{2}{|c|}{ Hypothetical without pre-emptions } & \multicolumn{2}{|c|}{ Real with pre-emptions } \\
\hline & GAP H (e-mail) & GAP V (disruptive) & GAP H (e-mail) & GAP V (disruptive) \\
\hline Scheduler 1 & Inf* & Inf* & Inf* & Inf* \\
\hline Scheduler 2 & $4 \%$ & $124 \%$ & $5 \%$ & $125 \%$ \\
\hline Scheduler 3 & Inf* & Inf* & Inf* & Inf* \\
\hline Scheduler 4 & $2 \%$ & $98 \%$ & $1 \%$ & $112 \%$ \\
\hline Scheduler 5 & $9 \%$ & $121 \%$ & $9 \%$ & $124 \%$ \\
\hline Scheduler 6 & $6 \%$ & $113 \%$ & $6 \%$ & $116 \%$ \\
\hline Scheduler 7 & $14 \%$ & $41 \%$ & $19 \%$ & $41 \%$ \\
\hline
\end{tabular}

*The system becomes unstable with actual behavioral parameters

Adapted from Larco et al. (2015)

\section{Conclusions and future research}

There has been recent work on studying white collar work. However, such literature focuses mainly on the discretion of task durations (see for example, Hopp et al. (2007) and Tan \& Netessine (2014)), We contribute by studying the discretion on task workflow decisions themselves, where the schedulers can decide on how often to engage in e-mail or decision support monitoring tasks as well as to preempting a task. In this way, we are able to assess the responsiveness of the scheduler, separating contextual parameters related to the work done from behavioral parameters related to the scheduler's capacity to control the workload.

Our main finding is that while checking e-mail more often may yield an improvement in the response times to incoming urgent e-mail requests, such improvement is at a cost of response times to disruptive events. By comparing the actual schedulers' responsiveness with the efficient frontier and non-dominated solutions, we show that greater relative improvements may be achieved in responsiveness to future disruptions than to e-mail checking. This fact can be explained by the relative higher frequency of incoming e-mail requests compared to the frequency of disruptions in the cases studied. Hence, more attention tends to be directed to e-mail requests. We believe this to 
be the case in most scheduling situations given the growing presence of high frequency emailing in many companies.

A counterintuitive result is that whenever utilization was high, more e-mail checking and a higher level of self-interruptions actually improved responsiveness to urgent tasks because queues are usually filled with non-urgent tasks, and thus, in these cases, being able to prioritize by checking potential incoming urgent requests may be beneficial. This is an interesting observation in our study, opening opportunities for further research.

Our results suggest that behavioral remedies may be especially important for the scheduler context extending earlier insights from the behavioral operations literature (Croson et al., 2013). Reversing unstable scheduling systems implies avoiding out of control disruptions that may have dire consequences such as lost sales, lost clients or overstock situations. We show in two specific cases that limiting the e-mail checking frequency, may bound infinite response-times to become finite. Providing feedback to limit e-mail checking may be effective to reduce such frequency. Other behavioral intentions may include redesigning decision support systems to provide alerts and feedback on the time elapsed since the last time stocks or production orders have been monitored.

The results on this paper, have been focused on the perspective of a single scheduler, however a natural extension could explore work interdependencies of the scheduler with its stakeholders where requests are no longer modelled exogenously but endogenously in a white-collar work network. Future research on potential fixes such as alerts in decision support systems for exceptions and disruptions as well as behavioral interventions for lowering expectations for replying to email can be explored. Moreover, a natural step for enhancing the understanding of the scheduling job is to study the interaction effects of workflow with actual job content, including the informational, decisional and interpersonal roles previously identified in the literature (Jackson et al., 2004).

Acknowledgments. This paper is a partial result of the project 4C4-More, which is supported by Dinalog, Dutch Institute for Advanced Logistics. The authors would like to also thank Professor Claudia Antonini for her valuable comments in improving this paper. Finally, the authors would 
like to thank the editor and anonymous reviewers whose constructive comments and suggestions helped us to improve the quality of this paper.

\section{References}

Anderson, J. R., D. Bothell, D., Byrne, M. D., Douglass, S., Lebiere, C., \& Qin, Y. (2004). An integrated theory of the mind. Psychological Review, 111, 1036-1060.

Bates, D. (2011), Linear mixed model implementation in lme4. url: http://cran.rproject.org/web/packages/lme4/vignettes/Implementation.pdf

Berglund, M., Guinery, J., \& Karltun, J. (2010). The unsung contribution of production planners and schedulers at production and sales interfaces. In Behavioral Operations in Planning and Scheduling (pp. 4781). Springer Berlin Heidelberg.

Burgess, P.W., E. Veitch, A. de Lacy Costello and T. Shallice (2000). The cognitive and neuroanatomical correlates of multitasking. Neuropsychologia, 38, 848-863.

Cegarra J. (2008) A cognitive typology of scheduling situations: a contribution to laboratory and field studies Theoretical Issues in Ergonomics Science, 9(3), 201-222.

Croson, R., Schultz, K., Siemsen, E., \& Yeo, M. L. (2013). Behavioral operations: the state of the field. Journal of Operations Management, 31(1-2).

Czarniawska-Joerges, B. (2007). Shadowing: and other techniques for doing fieldwork in modern societies. Copenhagen Business School Press DK.

De Snoo C, van Wezel W, Jorna RJ (2011) An empirical investigation of scheduling performance criteria. Journal of Operations Management, 29:2101-2122

Eisenhardt, K. M., \& Graebner, M. E. (2007). Theory building from cases: Opportunities and challenges. Academy of Management Journal, 50(1), 25-32.

Folk, C. L., R.W. Remington, J.C. Johnston (1992). Involuntary covert orienting is contingent on attentional control settings. Journal of Experimental Psychology: Human Perception and Performance 18(4), 10301044.

Gasser R., Fischer K., Wäfler T. (2010) Decision Making in Planning and Scheduling: A Field Study of Planning Behaviour in Manufacturing. In: Fransoo J., Waefler T., Wilson J. (eds) Behavioral Operations in Planning and Scheduling. Springer, Berlin, Heidelberg

Gonzales, V and G. Marks (2004). Constant, constant, multitasking craziness. In: Proceedings CHI 2004, ACM Press, 113-120.

Gralla, E. , Goentzel, J. and Fine, C. (2016), Problem Formulation and Solution Mechanisms: A Behavioral Study of Humanitarian Transportation Planning. Production \& Operations Management, 25: 22-35.

Hopp, W.J., S.M.R. Iravani and L. Fang (2009). White collar workforce management: An operationsoriented survey. Production \& Operations Management, 18(1), 1-32.

Hopp, W. J., Iravani, S. M., \& Yuen, G. Y. (2007). Operations systems with discretionary task completion. Management Science, 53(1), 61-77.

Jackson, T., Dawson, R., \& Wilson, D. (2001). The cost of e-mail interruption. Journal of Systems and Information Technology, 5(1), 81-92.

Jackson S, J.R. Wilson, and B.L. MacCarthy (2004). New model of scheduling in manufacturing: tasks, roles, and monitoring. Human Factors, 46(3), 533-550.

*Corresponding author: jlarco@utec.edu.pe, T: (511) 2305000 Ext. 4272, Jr. Medrano Silva 165, Barranco, Lima, Peru. 
Jett, Q.R. and J.M. George (2003). Source work interrupted: A closer look at the role of interruptions in organizational life. The Academy of Management Review, 28(3), 494-507.

Jersild AT. (1927). Mental set and shift. Archives of Psychology. 89, 1-81.

Larco, J., Fransoo, J, \& Wiers, V. (2015). Human factors of a 4C. In de Kok, A.G., Dalen, van, J., \& Hillegersberg, van J. (Eds.), Cross-Chain Collaboration in the Fast Moving Consumer Goods Supply Chain (pp.97-110) Retrieved from https://www.dinalog.nl/cross-chain-collaboration-in-the-fast-movingconsumer-goods-supply-chain/

Kushleyeva, Y., D.D. Salvucci, F. J. Lee (2005). Deciding when to switch tasks in time-critical multitasking. Cognitive Systems Research 6(1), 41-49.

Law, Averill M. (2015). Simulation modeling and analysis, 5th Edition. New York, NY: McGraw-Hill Education.

Larco-Martinelli, J. A., Fransoo, J. C., \& Wiers, V. C. S. (2018). Scheduling the scheduling task : a time management perspective on scheduling. Cognition, Technology \& Work, 20(1), 1-10.

Lee D.K., L. Itti, C. Kock, J. Braun (1999). Attention activates winner-take-all competition among visual filters. Nature Neuroscience, 2(4), 375-381.

Lee, H. L. (2004). The Triple-A Supply Chain. Harvard Business Review, 102-112.

Loomes, G. and R. Sugden. (1982). Regret theory: An alternative theory of rational choice under uncertainty. Economic Journal, 92, 805-2.

Logie, R.H., S. Trawley and A.S. Law (2011). Multi- tasking: multiple, domain-specific cognitive functions in a virtual environment. Memory and Cognition, 39,1561-1574.

MacCarthy, B. L., \& Wilson, J. R. (Eds.). (2003). Human performance in planning and scheduling. CRC Press.

Mark, G., V. Gonzales and J. Harris (2005). No task left behind? Examining the nature of fragmented work. In: Proceedings CHI 2005, ACM Press, 321-330.

McKay KN, Wiers VCS (1999) Unifying the theory and practice of production scheduling. Journal of Manufacturing Systems, 18(4):241-255

McKay, K.N. and V.C.S Wiers (2003). Planning, scheduling and dispatching tasks in production control. Cognition Technology Work 5, 82-93.

Monsell, S. P. (2003). Task switching TRENDS in Cognitive Sciences 7(3), 134-140.

Miyata, Y. and D. Norman Psychological issues in sup- port of multiple activities, In: User Centered Systems Design New Perspectives on Human Computer- Interaction, Hillsdale: Lawrence Erlbaum Associates, 265-284.

O'Conaill, B. and D. Frohlich (1995). Timespace in the workplace: dealing with interruptions. CHI Conference Proceedings, ACM, Denver, Colorado, USA.

Pashler, H., Johnston J.C., Ruthhruf, E. (2001). Attention and performance. Annual review psychology 52, 629-651.

Pinedo, M. (2005). Planning and Scheduling in Manufacturing and Services. Operations Research. Springer.

Renaud, K., J. Ramsay, M. Hair. 2006. "You've got email!” ... Shall I deal with it now? Electronic mail from the recipient's perspective. International Journal of Human-Computer Interaction 21(3) 313-332.

*Corresponding author: jlarco@utec.edu.pe, T: (511) 2305000 Ext. 4272, Jr. Medrano Silva 165, Barranco, Lima, Peru. 
Remington, R., J. Johnston and S. Yantis (1992). Involuntary attentional capture by abrupt onsets. Attention, Perception, \& Psychophysics 51(3) 279- 290

Romero-Silva, R., Santos J., Hurtado M. (2015): A framework for studying practical production scheduling, Production Planning \& Control: The Management of Operations, 1-14.

Rossetti, M. D. (2015). Simulation modeling and Arena. John Wiley \& Sons.

Salvucci, D. D. (2005). A multitasking general executive for compound continuous tasks. Cognitive Science, 29, 457-492.

Sanderson PM (1991) Towards the model human scheduler. International Journal of Human Factors Manufacturing, 1(3):195-219

Subramaniam, V., A. S. Raheja \& K. Rama Bhupal Reddy (2005) Reactive repair tool for job shop schedules, International Journal of Production Research, 43:1, 1-23,

Suddaby, R. (2006). From the editors: What grounded theory is not. Academy of management journal, 49(4), 633-642.

Tan, T. F., \& Netessine, S. (2014). When does the devil make work? An empirical study of the impact of workload on worker productivity. Management Science, 60(6), 1574-1593

Theeuwes, J. (1992). Perceptual selectivity for color and form. Perception \& Psychophysics, 51, 599-606.

Theeuwes, J. (1991). Exogenous and endogenous control of attention: The effect of visual onsets and offsets. Perception \& Psychophysics, 49, 83-9.

Van Donselaar, K. H., Gaur, V., Van Woensel, T., Broekmeulen, R. A., \& Fransoo, J. C. (2010). Ordering behavior in retail stores and implications for automated replenishment. Management Science, 56(5), 766784.

Verbeek, M. (2004) A guide to modern econometrics. John Wiley and Sons, NJ, USA.

Voss, C., Tsikriktsis, N., \& Frohlich, M. (2002). Case research in operations management. International Journal of Operations \& Production management, 22(2), 195-219.

Webster, S., Azizoglu, M. (2001) Dynamic programming algorithms for scheduling parallel machines with family setup times. Computers \& Operations Research, 28 (2) 127-137.

Wiers VCS, Van Der Schaaf TW (1997) A framework for decision support in production scheduling tasks. Prod Plan Control 8(6):533-544

Wiers, V. C., \& de Kok, A. T. G. (2017). Designing, Selecting, Implementing and Using APS Systems. Springer.

Yantis, S. and J. Jonides (1990). Abrupt visual onsets and selective attention: Voluntary versus automatic allocation. Journal of Experimental Psychology: Human Perception and Performance, 16, 121-134.

Yantis, S. and J. Jonides, (1984). Abrupt visual onsets and selective attention: Evidence from visual search. Journal of Experimental Psychology: Human Perception and Performance, 10, 601-621. 